\title{
UNIVERSITY EDUCATION AND POVERTY DYNAMICSLINKAGESIN NIGERIA: A STATE LEVEL ANALYSIS USING LOGIT AND PROBIT MODELS
}

\author{
Osabuohien-Irabor Osarumwense*
}

\begin{abstract}
Poverty is said to exist when people lack the means to satisfy their basic needs. Thus, improving the educational attainment of the population is an important requirement to reduce poverty amid the populace and foster development. However, Nigeria with her wealth, still facing enormous challenge in effort made at national level to reduce poverty. The aim and objective of this study is to give insight into the factors that affect or influence poverty in spite of attainment of university education in Nigeria. Percentage data from thirty-six States of the country including the Federal Capital territory Abuja were collated and analyzed through a qualitative response model design. Results from the Probit and Logit models used for analysis reveal that of all variables analyzed, only percentage of household heads with poor educational background was significant at 5\% level for all variables analyzed. This indicates a situation that a state with degree educational level of household heads as 0.2 percent, is more likely to be poor when compared to non-poor degree educational level of household head. However, in other way to reduce effect of poverty on educated households, it is recommended that various states' government should provide graduates with the training and support necessary to help them establish a career in small and medium sized business.
\end{abstract}

Keyword: Poverty, University, Probit, Logit, Education

\footnotetext{
* Mathematics/Statistics Department, Ambrose Alli University, Ekpoma, Nigeria UniversitiSains Malaysia (USM), Penang, Malaysia.osabuohien247@gmail.com, osabuohienosa@aauekpoma.edu.ng
} 


\section{Introduction}

Education paves the way to empower people to obtain knowledge, have access to jobs and subsequently higher wages. This empowerment allows people to have access to basic health facilities, acquires economic power, etc. This also improves the health condition of the population. An enlightened or educated population is usually crisis free or minimizes its crises. Thus collier, 2007, reported that a country with a higher percentage of its youth in schools considerably reduces its risk of conflicts. Nigeria in-spite of enormous wealth is still facing numerous challenge in the effort made at national level to reduce poverty. It has been estimated that more than $70 \%$ of Nigerians are living on less than one US Dollar per day. In order to reduce poverty and achieve social and economic development goals, higher education is one of the most powerful means that can be relied on. Most people recognize its value for productivity and growth in developed countries, but some people inexplicably consider university education as a luxury for developing countries. However, the goal of higher education has long been identified as the process that develops the whole man; physically, mentally, morally and technologically to enable him function effectively in any environment in which they find themselves ,so that they may become more productive, self-fulfilling and attain self-actualization (Tawari, 1986). There is more evidence that the proportion of the population with better education highly correlates with levels of economic development. With this understanding, Oxaal (1997), develops the linkages between education and poverty in two ways: (i) investment in education as a poverty reduction strategy can enhance the skills and productivity among poor households; (ii) poverty is a constraint to educational achievement both at the macro-level (poor countries generally have lower levels of enrollment) and the micro-level (children of poor households receive less education). He also asserted that education is a key factor for confronting the multiple challenges of social dislocation, environmental degradation and poverty eradication. Hence, the importance of higher education is to provide quality education for the people so that they can assume leadership position in their immediate and external communities (Federal Government of Nigeria, 2004). For a satisfactory completion of a university education, degrees are awarded to worthy graduates.

There are growing numbers of unemployed youth among graduates, particularly at the tertiary level, which is causing a mismatch between educational output and requirements of the labour market. The quality and relevance of education have declined as academic resources, whether 
faculty, equipment or facilities, have become increasingly short in supply. In addition, teachers/lecturers/workers in the universities and schools are going on incessant strikes in support of their protests for either have been underpaid or unpaid for months perhaps years. Pensions are delayed and salaries/wages are frozen for several months and years. This leads to students' taking years to graduate. And many who manage to graduate know little or nothing and practically are not fit for the labour market.

As a result, the country (Nigeria) is saddled with more than 20 million unemployed or underemployed youth out of about 167 million people in 2012 (National Bureau of Statistics), a situation that is undermining living standards throughout the country. Under the National Rolling Plan for 2001-2003, the government envisaged growth in employment of 1.8 million jobs-600,000 a year-but that number was still a mere $26 \%$ of what is needed just to hold unemployment and underemployment constant among the educated youth. Figure 1 shows the various years at which graduates of tertiary institutions seem to be badly hit by unemployment. This makes up about 20 percent of youth unemployment and often remaining unemployed for upward of five years after graduation (NISER, 2013).

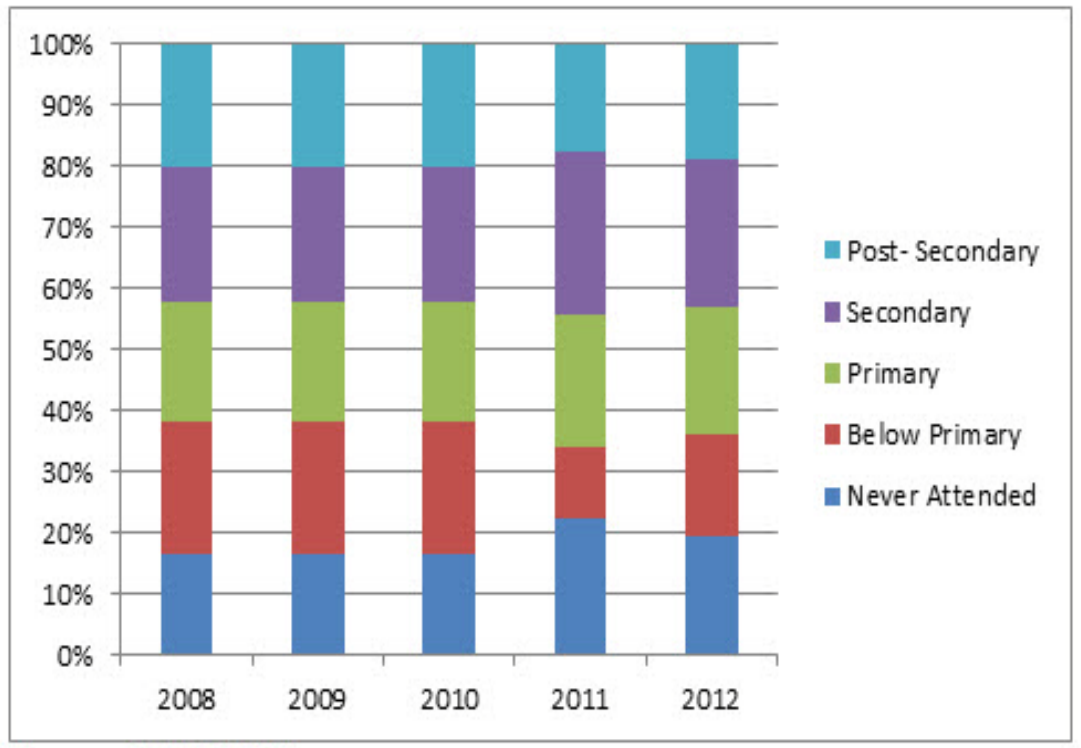

Source: NISER, 2013

Figure 1. National Youth Unemployment Figures (15 - 34 years) by Education, $2008-2012$ 
There are a total of one hundred and four (104) universities in Nigeria - forty four (44) private, forty-four (44) state, and twenty-six (26) federal universities turning out various graduates. Nigeria's education system turns out more than 3 million secondary and tertiary graduates every year, but it is estimated that the economy can absorb only around $10 \%$ of these graduates annually - Nigeria Ministry of Finance, (2000). Table 1 shows the various academic session of graduate output from Nigeria Universities. There has been steady increment in graduate output from Nigeria's universities, a proof shown in Table 1. $2000 / 2001$ to $2004 / 2005$ academic session revealed this much-talk about increment.

Table 1

Bachelor's Degree Graduate Output by Faculties from 2000/2001 - 2004/ 2005 Sessions

\begin{tabular}{|c|c|c|c|c|c|c|c|c|c|c|c|}
\hline & \multicolumn{2}{|c|}{$2000 / 2001$} & \multicolumn{2}{|c|}{$2001 / 2002$} & \multicolumn{2}{|c|}{$2002 / 2003$} & \multicolumn{2}{|c|}{$2003 / 2004$} & \multicolumn{3}{|c|}{$2004 / 2005$} \\
\hline Faculty & $M$ & F & M & $F$ & M & F & M & F & M & $\mathrm{F}$ & Total \\
\hline Administration & 3294 & 2298 & 4727 & 3413 & 6380 & 5321 & 4089 & 3201 & 2521 & 1843 & 37087 \\
\hline Agriculture & 1086 & 604 & 1366 & 705 & 1366 & 873 & 1268 & 828 & 299 & 167 & 8562 \\
\hline Arts & 2732 & 2351 & 2938 & 2982 & 3672 & 3963 & 2706 & 2746 & 1687 & 1495 & 27272 \\
\hline Education & 4129 & 4117 & 3221 & 3248 & 3560 & 3391 & 2361 & 3008 & 2352 & 2095 & 31482 \\
\hline Eng/Tech & 4194 & 581 & 4558 & 679 & 5425 & 800 & 4182 & 689 & 1051 & 116 & 22275 \\
\hline Envirn. Sc. & 932 & 375 & 1079 & 395 & 1201 & 560 & 940 & 368 & 643 & 243 & 6736 \\
\hline Law & 1558 & 990 & 2112 & 1781 & 2846 & 2664 & 1901 & 1461 & 1007 & 626 & 16946 \\
\hline Medicine & 1200 & 568 & 1538 & 613 & 1489 & 903 & 1219 & 721 & 359 & 230 & 8840 \\
\hline Pharm. Sc. & 242 & 78 & 312 & 138 & 186 & 144 & 320 & 235 & 12 & 10 & 1677 \\
\hline Sciences & 4743 & 2494 & 4461 & 2840 & 5839 & 4347 & 4390 & 2581 & 2190 & 1379 & 35264 \\
\hline Social Sc. & 5021 & 3223 & 8459 & 4996 & 8187 & 5856 & 6017 & 4220 & 2893 & 2296 & 51168 \\
\hline Dentistry & 0 & 0 & 45 & 22 & 67 & 30 & 48 & 21 & 0 & 0 & 233 \\
\hline Vet. Medicine & 68 & 19 & 99 & 47 & 155 & 54 & 47 & 21 & 30 & 6 & 546 \\
\hline Others & 583 & 311 & 1059 & 457 & 879 & 401 & 617 & 214 & 273 & 209 & 5003 \\
\hline Total & 29782 & 18009 & 35989 & 22316 & 41252 & 29109 & 30105 & 20314 & 15327 & 10715 & 252918 \\
\hline Grand Total & & 791 & 58 & & & 361 & & 419 & 26 & & \\
\hline
\end{tabular}

Source: National Bureau of Statistics Social Statistics in Nigeria (2005:37) 


\section{Literature Review}

There has been much debate on whether the attainment of university education influences the rates of poverty dynamics. If basic education and poverty has strong positive correlation, then it becomes logical fact that stronger positive relationship exist between higher education, particularly university education, and poverty reduction (Akooje and Mcgrath, 2005). Nigeria is about the $27^{\text {th }}$ poorest country in the world, where more than $60 \%$ of its population lives on less than $\$ 1$ a day (United Nations Economic Commission for Africa, 2002). This shows that the rate of incidence of poverty is extremely high.

Theoretical and empirical analysis tells that university education is a key to job creation and unemployment is a major cause of poverty. It is evident that countries with higher levels of education achievement have lower levels of poverty (Dollar \& Kraay, 2002). Therefore, higher levels of education enrollment in school and hence a resultant higher level of educational achievement can be a result of lower parental poverty levels, where parents or household have enough income to invest in their children's education (Adetanwa \& Olabisi, n.d); (Gom, 2008); (Rahman, 2006)). However, large and fast growing unemployment rate amongst Nigerian university graduates has become anintimidating situation. Education and poverty has become a major research issues for economists and statisticians for a few decades now, but unfortunately, very few researches and few empirical studies exist in Nigeria's perspective. This research aimed at studying the factors as well as the probabilities that influence poverty in spite of attainment of university education. Therefore, this study is a "big plus" to the scanty empirical analysis of poverty and attainment of university education in Nigerian context.

Vener, (2004), investigates the marginal impact of each individual attribute on the likelihood of a household falling below the indigence poverty line in Paraiba, Brazil, taking into account other characteristics. The study reveals two important and remarkable findings: (i) a conditional correlation between poverty and characteristics of household heads and (ii) information about groups that are particularly vulnerable in 1999. The probability of a household being poor is analyzed based on relevant individual and household characteristics. One of the salient findings is that poverty can be attributed to the lack of income-generating assets, particularly human capital.

In another investigation, Brown and Park (2002) specifically examined the effect of poverty on the educational enrolment and outcomes of children aged 5-16, using a 1997 survey of households and 
schools from poor countries in six provinces. Their measure of household wealth was expenditure per capita (excluding expenditure on education), and they defined a household to be 'poor and credit constrained' if it is in the bottom third of both expenditure per capita and access to credit. Using a proportional hazard model, they found that children are more likely to drop out of school if the household is poor and credit-constrained, if they have fewer siblings, if the father makes enrollment decision, and if school fees are lower. The sibling result was interpreted as indicating that siblings are complementary rather than competitors of resources, and the fees improve the quality of education and hence the rate of return. The authors found the test score (for enrolled pupils) to be higher if expenditure per capita is higher (implying that it improves quality) if there are older siblings, and for girl (suggesting that the less able girls drop out of school). However, their variables representing school quality (the pupil-teacher ratio, the proportion of rain-proof classrooms, and proportion of teachers with post-secondary education) had no significant effects on test scores. The aim and objective of this study is to give insight into the factors that affect or influence poverty in spite of attainment of University education in Nigeria.

\section{Methodology}

The data used in this study was collected from the office of statistics as recorded in the annual statistical bulletin 2012, for 36 states in Nigeria, including the federal Capital territory FCT. The main interest specifically is to use and collect state's information on percentage of household size of absolute poverty, percentage of national unemployment rate by state, percentage distribution of person's age; 15years and above by marital status, regional location of states, percentage distribution of persons by age group and percentage educational level of house head by absolute poverty etc. A number of different approaches have been used to understand the factors associated with poverty dynamics and poverty transitions. This study aimed to determine whether the attainment of university education affects rate of poverty dynamics in Nigeria. Given the dynamic and dichotomous nature of this study, a qualitative response model is appropriate. This relates to the probability of an event to various explanatory variables. In order to provide a detailed analysis, the discrete probit and logit models are used. The logit and probit models are the most commonly used members of the 
family of generalized linear model. Response variables in binary logit and probit models have two categories. Been a binary response, I write;

$$
\begin{aligned}
& P_{r}(y=1 / x)=G\left(\beta_{1}+\beta_{2} x_{2}+\ldots \ldots \ldots \ldots \ldots \ldots \ldots+\beta_{K} x_{K}\right) \\
& P_{r}(y=1 / x)=G(x \beta)
\end{aligned}
$$

Where;

$$
x \beta=\beta_{1}+\beta_{2} x_{2}+\ldots \ldots \ldots \ldots+\beta_{k} x_{k}
$$

Where $G$ is a cumulative density function taking values between zero and one: $0<G(z)<1$, for all real numbers $\mathrm{z}$;

$\left.\begin{array}{l}\text { (a) } P_{r}(y=1 / x) \rightarrow 1 \text { as } x \beta \rightarrow \infty \\ \text { (b) } P_{r}(y=1 / x) \rightarrow 0 \text { as } x \beta \rightarrow-\infty\end{array}\right\}$

Where (3) (a) is the probability of household heads from 36 states including the FCT, with university education being poor. The logit model given as;

$P_{r}(y=1 \mid x)=G(x \beta)=\frac{\exp (x \beta)}{1+\exp (x \beta)}=\Lambda(x \beta)$ below,

In the probit model, $G$ is the standard normal CDF as expressed

$P_{r}(y=1 \mid x)=G(x \beta) \int_{-\infty}^{x \beta} \phi(z) d z$

Where $\phi(z)=\frac{\exp \left(-\frac{z^{2}}{2}\right)}{\sqrt{2 \prod}}=\frac{1}{\sqrt{2 \prod}} \exp \left(-\frac{z^{2}}{2}\right)$

The probability of observing the entire sample in this study is;

$$
L(y \mid x ; \beta)=\prod_{i \in l} G\left(x_{i} \beta\right) \prod_{i \in m}\left[1-G\left(x_{i} \beta\right)\right]
$$

Where $l$ refers to observations for which $y=1$, and $m$ to the observation for which $y=0$. And the log likelihood for the sample is given as;

$\operatorname{InL}(y \mid x ; \beta)=\sum_{i=1}^{N}\left\{y_{i} \ln G\left(x_{i} \beta\right)+\left(1-y_{i}\right) \ln \left[1-G\left(x_{i} \beta\right)\right]\right\}$ 
Therefore, log likelihood for the logit and probit models respectively as shown in (8) are;

$$
\left.\begin{array}{l}
\operatorname{InL}(y \mid x ; \beta)=\sum_{i=1}^{N}\left\{y_{i}\left[x_{i} \beta-\operatorname{In}\left(1+\exp \left(x_{i} \beta\right)\right]-\left(1-y_{i}\right) \operatorname{In}\left(1+\exp \left(x_{i} \beta\right)\right)\right\}\right. \\
\operatorname{InL}(y \mid x ; \beta)=\sum_{i=1}^{N}\left\{y_{i} \operatorname{In} \Phi\left(x_{i} \beta\right)+\left(1-y_{i}\right) \operatorname{In}\left(1-\Phi\left(x_{i} \beta\right)\right)\right\}
\end{array}\right\}
$$

The logit and probit models stated in (4) and (5) was given by (Johnston and DiNardo, 1997).

Response Variable:

$$
y= \begin{cases}1 & \begin{array}{l}
\text { if State \% population of household with a } \\
\text { university degree is poor (PHUD) }
\end{array} \\
0 & \text { Elsewhere }\end{cases}
$$

The logit and probit models give similar characteristics of the data because the densities are very similar. Both approaches are much preferred to the linear probability model (Chris, 2007). However, our point of interest here relates to the probability that y equals one.

\section{Results}

The explanatory variable used in the logit and probit model are presented in Table 2 . The parameter estimation of household poverty with a university degree as a rate of response variable for logit and probit model is;

$$
\begin{aligned}
& \text { PHUD } \\
& \text { P }_{i}+\beta_{1} \text { PHHED }+\beta_{2} \text { PUNEM }+\beta_{3} \text { PRLOS }+\ldots \ldots \ldots . . \\
& \ldots . .+\beta_{11} \text { PPMHH }+\varepsilon
\end{aligned}
$$


Table 2

The description of variable used in the logit and probit analysis

\begin{tabular}{lll}
\hline Explanatory & Type & Description of variables \\
\hline PHHED & Binary & Educational level of household by States \\
PUNEM & Continous & National Unemployment rate by States \\
PRLOS & Binary & Regional location of States \\
PMMST & Binary & Married Marital Status by States \\
PAG29 & Continous & Distr of person by age group of between $15-29$ \\
PAG64 & Continous & Distr of person by age group of between $60-64$ \\
PHRHT & Continous & Housing Tenure (Rented apartment) \\
PINC A & Continous & Household monthly income of N1000 \\
PINC B & Continous & Household monthly income of N10000 - N19999 \\
PINC C & Continous & Household monthly income of N80000 \& above \\
PPMHH & Binary & Male Gender of Household head by States \\
\hline
\end{tabular}

\section{Source: Author's Calculation}

The binary logit and probit estimation was done by NewtonRaphson algorithm using the Maximum Likelihood estimation (ML), and convergence achieved after 8 iterations. The probit and logit models were used both to estimate the impact of the explanatory Variables, shown in Table 2 and to predict probabilities of change in the response variables levels. The ML estimate of $\beta$ in (9) gives the greatest likelihood of observing the sample, conditional on the explanatory variables $x$. The probability of observing that a state population of household head with a university degree is poor $\left[y_{i}=1\right]$, is $G(x \beta)$ while the probability of observing $y_{i}=0$ is $1-G(x \beta)$. The Pseuso- $\mathrm{R}^{2}$ values in predicting the actual observation of $y_{i}$ for both models (logit and probit) are 0.649 and 0.652 respectively, resulting in the log likelihood values at -7.9737 and -7.9095 approach zero from below- as discuss by Söderborn M. (2011). This shows fitness of the used models. The log likelihood ratio is often used to test whether a sub-set of the explanatory variable can be omitted from the model. The significance of the likelihood ratio test at 0.00879 and 0.00841 respectively also shows the adequacy of the models as shown in Table 3 and Table 4. 
The following hypothesis was set-up for both logit and probit models;

$H_{0}: \beta_{1}=\beta_{11}=0 \mathrm{Vs} H_{1}$ : the $\beta_{1 i}$ are not equal to zero

In equation (10), a p-value for both models at 0.729 and 0.575 , with chi-square(11) values of 7.815 and 9.501 respectively for the logit and probit models, showing a complete rejection of the Null hypothesis, that all parameters are equal to one.

Table 3

Estimated binary Logit values for Marginal and Average partial effects

\begin{tabular}{|c|c|c|c|c|c|c|c|}
\hline \multirow{2}{*}{ Variables } & \multicolumn{2}{|c|}{ Parameter Est. } & \multicolumn{2}{|c|}{ Marginal Effects } & \multicolumn{2}{|c|}{ Average Partial Eff. } & \multirow{2}{*}{ Signif. } \\
\hline & Estimate & Std.Err. & Estimate & Std.Err. & Estimate & Std.Err. & \\
\hline Constant & -7.9876 & 24.4489 & & & & & 0.7438 \\
\hline PHHED & 4.2709 & 2.1977 & 0.1976 & 0.1017 & 0.2769 & 0.1055 & 0.0519 \\
\hline PUNEM & 0.0233 & 0.1123 & 0.0010 & 0.0052 & 0.0015 & 0.0072 & 0.8353 \\
\hline PRLOS & 4.1410 & 4.2448 & 0.1916 & 0.1964 & 0.2685 & 0.2762 & 0.3292 \\
\hline PMMST & -0.0888 & 0.1863 & -0.0041 & 0.0086 & -0.0057 & 0.0120 & 0.6336 \\
\hline PAG29 & -0.0628 & 0.4084 & -0.0029 & 0.0189 & -0.0040 & 0.0264 & 0.8777 \\
\hline PAG64 & 1.5677 & 2.0148 & 0.0725 & 0.0932 & 0.1016 & 0.1310 & 0.4365 \\
\hline PINCC & 0.3932 & 0.3146 & 0.0182 & 0.0145 & 0.0254 & 0.0190 & 0.2113 \\
\hline PHRHT & -0.1017 & 0.1830 & -0.0047 & 0.0084 & -0.0066 & 0.0117 & 0.5781 \\
\hline PINCA & 0.0350 & 0.2872 & 0.0016 & 0.0132 & 0.0022 & 0.0185 & 0.9029 \\
\hline PINCB & 0.1165 & 0.2389 & 0.0053 & 0.0110 & 0.0075 & 0.0153 & 0.6257 \\
\hline PPMHH & 0.0221 & 0.1225 & 0.0010 & 0.0056 & 0.0014 & 0.0079 & 0.8563 \\
\hline $\begin{array}{l}\mathrm{L} \\
\mathrm{L}\end{array}$ & $\begin{array}{l}\text { kelihood } \\
\text { kelihood }\end{array}$ & $\begin{array}{l}-7 . \\
-20\end{array}$ & $\begin{array}{l}7 \\
72\end{array}$ & $\begin{array}{r}\text { Pseu } \\
\text { Test of }\end{array}$ & $\begin{array}{l}2^{\wedge} 2 \\
\text { ficients (1 }\end{array}$ & $\begin{array}{l}0.6497 \\
25.1070\end{array}$ & \\
\hline
\end{tabular}

\section{Source: Author's Calculation}

As seen and expected in Tables 3 \& 4, all estimated values of logit and probit models for Parameter estimates, Marginal Effects and Average partial Effects are very close. Where all value of the variables used in this study are in percentages (\%). Only the PHHED variable seems significance at $5 \%$ level. The marginal effects - the effects on the response probability $P_{r}(y=1 / x)$ resulting from a change in one of the 
explanatory variables evaluated at the mean shows that a poor household head with university degree is $0.2 \%$ more likely than non-poor household heads with university education.

Table 4

Estimated binary probit values for Marginal and Average partial effects

\begin{tabular}{|c|c|c|c|c|c|c|c|}
\hline \multirow{2}{*}{ Variables } & \multicolumn{2}{|c|}{ Parameter Est. } & \multicolumn{2}{|c|}{ Marginal Effects } & \multicolumn{2}{|c|}{ Average Partial Eff. } & \multirow{2}{*}{ Signif. } \\
\hline & Estimate & Std.Err. & Estimate & Std.Err. & Estimate & Std.Err. & \\
\hline Constant & -4.4112 & 13.0514 & & & & & 0.7353 \\
\hline PHHED & 2.4489 & 1.2034 & 0.2329 & 0.0519 & 0.2863 & 0.0626 & 0.0418 \\
\hline PUNEM & 0.0125 & 0.0551 & 0.0011 & 0.0023 & 0.0014 & 0.0035 & 0.8204 \\
\hline PRLOS & 2.3672 & 2.3716 & 0.2251 & 0.1023 & 0.2768 & 0.1557 & 0.3181 \\
\hline PMMST & 0.0489 & -0.1072 & -0.0046 & 0.0046 & -0.0057 & 0.0069 & 0.6477 \\
\hline PAG29 & -0.0365 & 0.2176 & -0.0034 & 0.0093 & -0.0042 & 0.0142 & 0.8667 \\
\hline PAG64 & 0.8911 & 1.0362 & 0.0847 & 0.0447 & 0.1042 & 0.0679 & 0.3898 \\
\hline PINCC & 0.2266 & 0.1587 & 0.0215 & 0.0068 & 0.0265 & 0.0097 & 0.1533 \\
\hline PHRHT & 0.0588 & -0.1027 & -0.0055 & 0.0044 & -0.0068 & 0.0066 & 0.5668 \\
\hline PINCA & 0.0081 & 0.1643 & 0.0007 & 0.0070 & 0.0009 & 0.0107 & 0.9602 \\
\hline PINCB & 0.0646 & 0.1298 & 0.0061 & 0.0056 & 0.0075 & 0.0084 & 0.6184 \\
\hline \multirow[t]{2}{*}{ PPMHH } & 0.0106 & 0.0683 & 0.0010 & 0.0029 & 0.0012 & 0.0044 & 0.8763 \\
\hline & \multicolumn{2}{|c|}{ Log Likelihood } & -7.9095 & \multicolumn{2}{|c|}{ Pseudo-R^2 } & \multicolumn{2}{|l|}{0.6529} \\
\hline & (Base) & \multicolumn{5}{|c|}{-20.5272LR Test of Coefficients (11) $\quad 25.2354$} & \\
\hline Significanc & evel of LF & \multicolumn{6}{|c|}{0.0084 Chi-Squared $(11)=9.5016$ with Significance Level 0.5756} \\
\hline
\end{tabular}

Source: Author's Calculation

\section{Discussion and Conclusions}

This study examined analysis of factors that affects the probability of being poor given the attainment of university education. Only percentage of household heads with poor educational background was significant at 5\% level for all variables analyzed. Results show that a poor household head with university degree is $0.2 \%$, more likely than non-poor household heads with university education. This connotes that a state with degree educational level of household heads is 0.2 percent, more likely to be poor when compared to non-poor degree educational level of household head. This translates to mean that a poor degree educational level of household heads from state would more likely 
translate to poor educational level of state's population. However, as shown in Tables 3 and 4, other analyzed variables, like Region, Marital status, have no influence on the relationship between university education and poverty.

However, in order to reduce effect of poverty on educated households, it is recommended that various state governments should provide graduates with the training and support necessary to help them establish a career in small and medium sized business. These skills training will make them meet the manpower needs of society. Students who would have contributed immensely towards the development of the country are found studying programmes, in which they do not have the requisite requirements and knowledge. This is a case of fixing square pegs into round holes and this has contributed into a high number of unemployed graduates who are taking time to identify where exactly they can fit in among the various sectors of the economy. Therefore, academic institutions at all levels including tertiary institutions should ensure that students who have no bases being in school should be advised to withdraw and re-directed to other areas or trade like Vocational and technical training.

\section{REFERENCES}

Akooje, S. and McGrath, S. (2005). Post-basic Education and Training and Poverty Reduction in South Africa: Progress to 2004 and vision to 2014, Post-basic Education and Training, working paper series - No.2, Centre of African Studies, University of Edinburgh.

Brown P. and Park A. (2002). Education and Poverty in Rural China, Economics of Education Review, 21: 523- 541.

Chris B. (2007). Introductory Econometrics for Finance, second edition, Cambridge University press, Edinburg building, Cambridge CB2 8RU, UK.

Collier, P. (2007). Economic Causes of Civil Conflict and their Implications for Policy, in leashing the Dogs of War: conflict management in a divided world. USIP Press Books.

Dollar, D., \& Kraay, A. (2002). Growth is good for the Poor. Journal of Economic Growth, 7(3): 195-225.

Dunga, S. (2012).Determinants of Primary Education Quality in Developing Countries: Factors that Matter. London: LAP.

Federal Government of Nigeria (2004). National Policy on Education (Revised Edition).Abuja, Nigeria Education Research and Development Council. 
GoM. (2008). Education sector Implementation Plan 2009-217. Lilongwe: Malawi Government.

Johnston J. and DiNardo J., Econometric Methods, (4th Edition), McGraw-Hill, 1997 (an up-dated version of Johnston's classic text).

Nigeria Ministry of Finance, 2000a.National rolling plan, 2001-2003. Abuja. Organisation for Economic Cooperation and Development (OECD), 2012. Gender equality in education, Employment and entrepreneurship: Final Report to the MCM, C/MIN 5.

NISER (2013): Analysis and Design of Safety Nets and Capacity Empowerment Program for unemployed Youth in Nigeria.

NSO. (2012). Integrated Household Survey 3 (IHS 3). Zomba: Malawi Government Press.

Söderborn Mäns, (2011). Applied Econometrics, Binary Choice Models. University of Gothenburg

Tawari, O. C. (1986). A Study of the Perceived Adequacy of Student Support Services in Nigeria Universities. Unpublished Doctoral Dissertation, University of Benin, Benin City, Nigeria.

United Nations Economic Commission for Africa (2002).Economic report on Africa: Tracking performance and progress, Addis Ababa, Ethiopia.

Vener, D., 2004. Education and its Poverty-Reducing Effects: The case of Paraíba, Brazil, World bank policy research, Working Paper, 3321.

Zoë Oxaal, 1997. Education and Poverty. A Gender Analysis, report prepared for the gender equality unit, Swedish international development cooperation agency (SIDA), Institute of development studies, University of Sussex, UK.

Received on: June 1, 2015

Revised on: December 20, 2015

Accepted on: December 22, 2015 